\title{
O Filho Eterno: Um elemento entrópico na família
}

\author{
O Filho Eterno: An element entropy in the family
}

"As famílias. Família é um horror, mas um horror necessário - ou inevitável, o que dá no mesmo.

Agora terei a minha família, ele pensa." (TEZZA, 2008, p. 24).

Claudia Regina Manzolillo ${ }^{1}$

RESUMO: Em O Filho Eterno, romance vencedor do Prêmio Jabuti 2008, Cristóvão Tezza desvenda um universo de sensações desagradáveis experimentado nas relações familiares. $\mathrm{O}$ personagem-narrador rememora situações dramáticas: o casamento, permeado pela dificuldade econômica e a falta de realização profissional, e o nascimento do filho com Síndrome de Down. Esse percurso de fracassos, de oscilações de sentimentos entre negação e aceitação, marca a narrativa, que beira, em certos momentos, a crueldade. Entretanto, há um turning point. A saga por uma possível cura e o resgate de um pai amoroso, protegido por uma couraça emocional, eclodem durante a narrativa. De certa forma, o filho constrói o pai nesse texto que trata de limitações humanas e demonstra que a barreira do impossível é quebrada pelo amor.

PALAVRAS-CHAVES: Cristovão Tezza; memória; família; filho; down.

ABSTRACT: In O Filho Eterno, book winner of the 2008 Jabuti Prize, Cristóvão Tezza unveils a universe of unpleasant sensations experienced in family relationships. The narrator-character recalls dramatic situations: marriage, permeated by economic difficulty and lack of professional achievement, and the birth of the child with Down's Syndrome. This path of failures, of oscillations of feelings between denial and acceptance, marks the narrative, which borders, at certain moments, to cruelty. However, there is a turning point. The saga for a possible cure and the rescue of a loving father, protected by an emotional armor, hatch during the narrative. In a way, the son builds the father in this text that deals with human limitations and shows that the barrier of the impossible is broken by love.

KEY-WORDS: Cristovão Tezza; memory, family, son; down.

A epígrafe deste artigo funciona como a anunciação de um novo estágio na vida "dele e dela". Um homem, uma mulher: um casal. Um homem, uma mulher, uma criança. Com essa constituição, forma-se um núcleo familiar que, de acordo com os ideais estabelecidos pela sociedade da segunda metade do século XX, deve se ajustar ao conceito de família perfeita. Para os padrões da época, ao homem pertence o papel de provedor. É dele a responsabilidade pela família, atribuição que carrega desde os primórdios da

1 Escritora (autora de A Dona das Palavras), é mestra em Literatura Brasileira pela UFRJ. E-mail: cmanz@globo.com. 
civilização. Caçador, ele provê o alimento. Modernamente, traz os resquícios desse comportamento arraigados na memória atávica. Agora, ele sai em busca do trabalho, do sustento para a família. A mulher, a dona do lar, também vai se despindo da roupagem ancestral e procura novos trajes, novas metas, expandindo seus múltiplos talentos além das fronteiras do domus. Ela está construindo um novo perfil, saindo do claustro familiar, passando a dominar os dois mundos: o do lar e o do trabalho. Ela deixa de ser apenas a coadjuvante. Ela é aquela que galga os degraus para sua total independência.

O filho é a peça que liga marido e mulher, sendo, às vezes, o único elo entre os dois. O filho transforma o casal em uma família. O filho é pensado como a união entre os dois. Mesmo em caso de separação, sempre haverá o filho. O filho é para quem pai e mãe se voltam no intuito de suprir-lhe as necessidades, de criar laços de afeto e de estruturar as possibilidades de aprendizado para um futuro sólido. O que se quebra quando o filho não corresponde às expectativas da família? O mundo se desequilibra, o casal se perde e talvez nem se recupere mais. A família não se constitui? A família, que nunca foi, será? Sobre essa ótica, será a feita a leitura de O filho eterno, de Cristóvão Tezza, livro de cunho autobiográfico, mas que foge aos parâmetros da autobiografia, uma vez que o autor consegue fazer de sua história de vida uma narrativa em que passa a ocupar o lugar de personagem de si mesmo, refazendo a via-crúcis em arte, em objeto estético. Em entrevista ao jornal Folha de São Paulo, o escritor declara como processou esse distanciamento: "É um exercício da crueldade. Esse é o principal atributo do narrador. Ele não pode ter piedade de nada e de ninguém... Quando comecei a escrever, todos os problemas pessoais e emocionais já estavam resolvidos. A questão era como transformar isso em literatura" (TEZZA, 2008, p. E1).

Esse exercício de crueldade a que se refere Tezza transformou-se em uma narrativa de reconstrução da identidade, em que um homem, assustado diante de um diagnóstico irreversível, vivencia uma reforma interior visceral a partir da relação amorosa, dos vínculos criados na convivência com o filho.

Distanciado o escritor da própria existência pelo fator tempo, ele permite-se olhar os acontecimentos e as emoções através do filtro de outros olhos: os do escritor em busca de uma história para transformá-la em criação literária.

Centrado nas relações familiares em um núcleo diferenciado, pai, mãe e um filho com síndrome de Down, o romance desmonta o sentido da perfeição para reinventar uma história familiar. A partir do título, verifica-se uma espécie de rompimento com o futuro, já que "eterno" se aplica a uma condição imutável, estática. Eterno seria aquele que, no plano 
metafísico, se condensou em outra realidade, por exemplo, a morte. No romance, a condição de eternidade está associada à dependência intrínseca ao portador da síndrome de Down. É um filho para sempre. Um filho num estágio, sem a pretensão de ir além. Um filho é eterno quando, consolidado na morte, vive na memória dos pais. Um amor eterno é a expressão dolorosa de um sentimento sublimado post-mortem. Eterno é o que transcende à materialidade. Eterno, neste romance, adquire uma carga semântica de dependência familiar e prolongamento da infância. Eterno também será o pai, já que deverá, apesar da rejeição inicial, assumir a função de cuidador do filho para além do período esperado.

Os assombros que essa nova situação traria se anunciavam normais como os de qualquer casal diante da vinda de um filho. O par estava prestes a se transformar num trio. Ele, naquela situação, era o amparo da mulher, o que já o colocava num lugar diferente daquele tão obscuro em que se julgava estar. Era o homem protetor, o pai daquele filho, prestes a rebentar: "A mulher que, em todos os sentidos, o sustentava já havia quatro anos, agora era sustentada por ele enquanto aguardava o elevador, à meia-noite. Ela está pálida. As contrações. A bolsa, ela disse - algo assim. Ele não pensava em nada - Em matéria de novidade, amanhã ele seria tão novo quanto o filho” (TEZZA, 2007, p.9).

A felicidade de ser pai o invadira. Sentia-se pleno, ainda que inseguro. Ele estaria adequado ao sistema que negara tanto, mas isso lhe dava uma sensação de segurança. Buscava ser um homem nos trilhos. Um chefe de família. Ele estava de acordo com a sociedade: "Por enquanto as coisas vão bem - ele não pensava no filho, pensava nele mesmo, e isso incluía a totalidade de sua vida, mulher, filho, literatura, futuro" (TEZZA, 2008, p.12)

E quando tudo contradiz o que se espera? E quando o socialmente aceito esbarra no geneticamente desconhecido? O primeiro filho está ali, e o mundo cai. As expectativas estão postas à mesa. Pai, mãe e filho, uma nova família, prestes a apresentar-se ao mundo que cobra perfeição. Está nitidamente organizada a peça a ser representada naquele palco. Algo não se enquadra, porém: "Sentimentos primários que se sucedem e se atropelam - ele ainda não entende absolutamente nada, mas a vida está boa. Ainda não sabe que agora começa um outro casamento com a mulher pelo simples fato de que eles têm um filho. Ele não sabe ainda de nada" (TELLES, 2008, p.29)

O cenário é ideal, como o de todas as salas de espera e quartos onde a vida se apresenta, mas ela (a vida) não pode ser apequenada, desconforme. Ela que não segue roteiros, surpreende a todos neste desenredo, que se divide em quatro atos: 
- Primeiro ato: o script

É um papel que representamos, o pai angustiado, a mãe feliz, a criança chorando, o médico sorridente, o vulto desconhecido que surge do nada e nos dá parabéns ... Há um cenário inteiro montado para o papel, e nele, deve-se demonstrar felicidade ( $\mathrm{p}$. 9-10). A mulher está plácida naquela cama de hospital - sim, sim, tudo vai bem... Eu fiz um curso de pai, ele alardeia, palhaço, fazendo piada... E as famílias falam e sugerem - chás, ervas, remedinhos, infusões, cuidados com o leite -, é preciso dar uma palmada para que ele chore alto... Os parentes estão animados, mas ele sente um cansaço subterrâneo (TEZZA, 2008, p. 28).

- Segundo ato: a expectativa

Súbito, a porta se abre e entram os dois médicos, e um deles tem um pacote na mão. Estão surpreendentemente sérios, pesados, para um momento tão feliz parecem militares. Há umas dez pessoas no quarto, e a mãe está acordada. É uma entrada abrupta, até violenta - passos rápidos, decididos, cada um se dirige a um lado da cama, com o espaldar alto: a mãe vê o filho ser depositado diante dela ao modo de uma oferenda, mas ninguém sorri... Todos se imobilizam - uma tensão elétrica, súbita, brutal, paralisante, perpassa as almas, enquanto um dos médicos desenrola a criança sobre a cama... Todos esperam (TEZZA, 2008, p.30).

- Terceiro ato: a revelação

Há o início de uma preleção, quase religiosa, que ele, entontecido, não consegue ainda sintonizar senão em fragmentos da vOZ do pediatra: - algumas características... sinais importantes... vamos descrever. Observem os olhos, que têm a prega nos cantos, e a pálpebra oblíqua... o dedo mindinho das mãos arqueado para dentro... achatamento da parte posterior do crânio... a hipotonia muscular... a baixa implantação da orelha e... (TEZZA, 2008, p.30).

- Quarto ato: a solidão

No momento em que enfim se volta para a cama, não há mais ninguém no quarto só ele, a mulher e a criança no colo dela... eu não preciso deste filho, ele chegou a pensar... também não preciso desta mulher... como sempre ele está sozinho (TEZZA, 2008, p.32).

Pensara anteriormente à chegada do filho: a nova situação - um pai de família - se configuraria como uma oportunidade de ser integralmente. Essa era a forma de passar a limpo a vida. A partir daquele filho, seriam - ele e a mulher - uma família, isso, para um menino órfão de pai como ele, representava uma forma de refazer o fio perdido e tecer uma família. Era como se ele renascesse e, quem sabe, dessa vez, tudo fosse conforme os padrões sociais, aqueles aos quais não conseguia se adequar. Faculdade de Letras incompleta, nenhum emprego seguro. Um ser incompleto que vive das migalhas da mulher, ela, sim, de acordo com os padrões, com um trabalho formal.

Ele e a mulher, um casal, a partir do filho, passavam a ser, de fato, uma família. O filho é o futuro que se apresenta ao homem. A máxima "o filho é o pai do homem" lhe oferecia a possibilidade de se passar a limpo. Rascunho de si mesmo, o filho será ele passado a limpo, um homem renascido. Nada será como tem sido: um vazio, uma lacuna 
impreenchível. A barriga da mulher é como um mundo novo, redondo, pronto a explodir. A bolsa. A vida. Ele, à espera. Um casal que se escora. Pilar um do outro, coluna rachada, o homem mais se apoia do que sustenta. A família, nos anos de 1970, não é isso. Há papéis engessados que devem ser cumpridos. Nos moldes da época, a mulher é uma das peças da família, mas ainda não é o pilar. É a escora, aquela que apara as arestas. No imaginário masculino, ele, agora, cumprirá o seu papel. Será o provedor, o marido, o pai. Um homem, uma mulher, um filho. Agora sim, ele estaria, de certa forma, dentro do sistema. Pelo menos, ele teria uma relação de pertencimento a uma instituição - a família: "Sim. Ele conseguiu parar porque não era um menino de rua: aos 15 anos, tinha uma boa escola, casa, mãe, família - e um desejo de virar o mundo pelo avesso. Agora, e ele sorri com a ficha na mão, agora, já alimentando a própria autoironia com que se defende do que seria a própria decadência. Um homem do sistema. Família é sistema” (TEZZA, 2008, p. 25-26).

O filho que virá, menino ou menina, é o impulso para ser o pai, o chefe da família num período em que os homens começavam a partilhar com suas mulheres o momento do parto. Entretanto, ele preferiu ficar de fora. A mulher lá, parindo. Ele, cá, na sala, fumando, pensando. Três, enfim!

O pai, até o nascimento do filho, sentia-se num estado provisório. Tal condição de precariedade sofrerá, no entanto, uma reviravolta. Ele, que se julga um nada, algo que não faz diferença, alguém que carrega o corpo apenas, sem uma nesga de esperança, passa a ser “o pai”. Ele, sustentado literalmente, por ela, alicerce e real provedora, papel inverso ao desempenhado pelas mulheres nos anos 1980, investe-se de significado. O filho refaz o casal, que passaria a ser, realmente, uma família como mandam os padrões: "Ainda não sabe que agora começa um outro casamento com a mulher pelo simples fato de que têm um filho. Ele não sabe nada ainda" (TEZZA, 2008, p. 29).

O laço familiar está ali, atado para sempre, assim como a dependência do filho está determinada para o casal. A revelação feita pelos médicos de que o filho é portador da Síndrome de Down vem a findar com todas as esperanças de ter uma versão aprimorada de si mesmo. Constata, então, a irreversibilidade da situação, a desestruturação que a nova realidade provoca. Pai e mãe têm de conviver com o estranho e inusitado, não há outra saída. O casal se mantém por um fio, mas eles se mantêm mesmo assim. O fio se fortalece. O luto é vivenciado pelos dois. Nessa sequência de emoções, resgatam-se valores familiares que não haviam sido construídos na relação entre homem e mulher. Unem-se, pai e mãe, mais do que antes para a reabilitação possível do filho. 
Os papéis tornam-se definidos a partir do nascimento do filho. Existem agora pai e mãe. O personagem-narrador autodenomina-se pai, deixando que essa circunstância se torne a principal em sua vida. Mesmo a contragosto, ele é o pai: o responsável. Deixa de lado o papel de marido, amante, companheiro para tomar-se todo da condição inalienável de um pai tão eterno quanto o filho, um dependente do outro, sem limites de subjetividade. Apesar de representar uma carga muito pesada para ele que, até então, mal conseguia carregar-se a si mesmo, que mal se definia na sociedade como professor, escritor, que era apenas alguém tentando se reconstruir, mesmo que num rascunho imperfeito, pois: "Ninguém está preparado para um primeiro filho, ele tenta pensar, defensivo, ainda mais um filho assim, algo que simplesmente ele não consegue transformar em filho" (TEZZA, 2008, p. 32).

Bolsa rebentada, vida rebentada. Assim, ao contrário do que o homem sonhara, o filho, com Síndrome de Down, dificulta a relação que já não se constituía plena em razão de os papéis marcados para marido (o provedor) e mulher (a provida) não se cumprirem como o esperado pelo status quo dos anos de 1970-1980. Então, a família bambeia como um tripé manco. O filho veio para desarmonizar o que se pretendia sólido. Culpas e rastros de uma relação desgastada minam a recém-família. A princípio, a dor da notícia. Não é perfeito? Como não? Como seguir uma vida planejada com "algo" que contraria as regras do aparentemente bom, apresentável e aceito. O que fazer dali em diante?

O casal anda em entropia. O filho é um ser entrópico naquele cenário. Nada será como há pouco, antes da gravidez, da bolsa explodindo no elevador, das horas passadas na sala de espera do hospital, antes do delírio de ser responsável por outro ser, antes do baque da notícia: Down. Um quadro sem moldura. Uma porta sem chave. A família incompleta. Nada dava certo para ele, um quase. Ele, sem nome. Ele, sem família. A mulher, sem nome. O filho, nomeado. Felipe, um nome forte. Um nome que, ao ser pronunciado, remontava à força dos cavaleiros medievais. Um filho a ser tudo aquilo que o pai não era, um homem cujos ideais esbarravam no quase. Um escritor, um marido, um pai quase. E o que fizera? Um filho quase. Uma família quase.

Logo após a revelação asséptica feita pelos médicos, o pai, destroçado, sem nem ao menos um vislumbre de integrar um conjunto "perfeito", renega a família: "Recusa. Recusar: ele não olha para a cama, não olha para o filho, não olha para a mãe, não olha para os parentes, nem para os médicos - sente uma vergonha medonha de seu filho e prevê a vertigem do inferno em cada minuto subsequente de sua vida” (TEZZA, 2008, p.32) 
também não preciso desta mulher, ele quase acrescenta, num diálogo mental sem interlocutor, como sempre, está sozinho (TEZZA, 2008, p.32).

A primeira criança de um casamento é uma aporrinhação monumental - o intruso exige espaço e atenção, chora demais, não tem horário nem limites, praticamente nenhuma linguagem comum, não controla nada em seu corpo, que vive a borbulhar por conta própria, depende de uma quantidade enorme de objetos (do berço à mamadeira, do funil de plástico às fraldas, milhares delas) até então desconhecidos pelos pais, drena as economias, o tempo, a paciência, a tolerância, sofre males inexplicáveis e intraduzíveis, instaura em torno de si o terror da fragilidade e da ignorância, e afasta, quase que aos pontapés, o pai da mãe. É uma criança - como todo recém-nascido - feia. É difícil imaginar que daquela coisa mal-amassada surja como que por encanto algum ser humano, só pela força do tempo (TEZZA, 2008, p. 73-74).

Um confronto entre o filho idealizado e o filho real se exacerba caso a criança apresente um tipo de deficiência. Sentimentos ambivalentes permeiam a vida do casal com a vinda do filho entrópico. Impossibilidade, desacerto, família abortada antes mesmo de ser, essa realidade o corrói. Busca escapar da teia. Quer libertar-se, mas sabe que eternamente será o pai: “... tem a mulher, mas eles não nasceram juntos. Podem se separar, e a ordem do mundo se mantém. Mas filho é outro nascimento: ele não pode se separar dele" (TEZZA, 2008, p. 20).

Surge, então, diante da verdade avassaladora, o jogo de acusações instaura a culpa, o peso transferido é para um dos membros do clã: "A mulher tem razão: ela acabou com a vida dele, ele suspira, concordando, e sente-se misteriosamente mais tranquilo" (TEZZA, 2008, p. 45). Apaziguado por um período, o pai tenta esquecer-se do filho, negando-o, apagando-o como uma frase mal redigida.

Contudo, o ideal de perfeição, ainda que um simulacro dela, não abandona o imaginário do recém-pai. A mulher pouco se manifesta. O pai delira com as possibilidades de livrar-se daquilo que não se integra ao padrão. Várias são as vezes em que se percebe a tentativa de solucionar o ato falho, mesmo que platonicamente. Quem sabe a morte precoce ou uma irônica descombinação entre aparência e essência? No fundo, gostaria de resolver o problema-filho. Que a vida, o destino resolvessem por ele. Tais pensamentos de libertação não o deixavam. Eram o leitmotiv de seus primeiros dias como pai.

Uma peregrinação incessante em busca de uma possível salvação/melhora (já que o livramento pela morte não seria possível) é o elemento catalisador desta família. Ele, ela e o filho, uma família, vão peregrinar para reconstruir-se do caos. Esse trio percorre médicos, clínicas. Pai, mãe se unem no processo de adequação do filho ao mundo, recolhendo esperanças aqui e ali. O não filho deixa esse não lugar, desconfortável e nulo, para ocupar o lugar da hipótese: "O pai ainda não sabe, mas começa a ter uma ideia de filho... Como se ... a sombra da paternidade começasse a cair sobre ele" (TEZZA, 2008, p. 68). 
O pai, aquele que desempenhava, tradicionalmente, o papel de provedor da família agora se apresenta e se manifesta nele, responsável pelo filho que necessita dele. A realidade é maior do que qualquer descolamento entre o que ele havia idealizado como um filho perfeito e o que está ali, ainda um mistério a ser decifrado.

Pai e mãe agora são uma família com a missão de tornar o filho um ser "igual" aos demais um laço entre o homem e a mulher naqueles tempos não tão longínquos em que a família era algo pasteurizado e aceitável pela sociedade como um oásis, o padrão de perfeição que cumpria ao homem gerir e à mulher criar e cuidar. Um filho desconforme aos modelos não é aceito pela sociedade de então. Sabe-se de casos em que o filho "problemático" é simplesmente excluído da família, trancado em casa, sem acesso a nenhum contato com o grupo social de seus pais.

No romance de Tezza, o pai toma para si toda a responsabilidade de cuidar e proteger o filho. É um código a ser decifrado. Um desafio a ser vencido. O pai mais do que a mãe representa a família. O pai toma para si a representação de "a família" de Felipe; a mãe fica em segundo plano, a outra filha, saudável, não interfere substancialmente no comportamento paterno, totalmente centrado no filho primogênito, aquele que seria uma folha passada a limpo do rascunho que fora a vida do pai.

A princípio, o sentimento em relação ao filho é de rejeição total àquela figura equivocada. No entanto, o pai reveste-se da função de guardião da vida do menino, um protetor permanente, tentando, a cada dia, subverter a sentença de impossibilidade do filho diante da vida. Laços atados, o pai é testado em seu sentimento de cuidador amoroso, o que culmina no episódio do desaparecimento (sequestro? Para quê quereriam uma criança assim? E assim aquietava-se o coração angustiado do pai).

O amor lapida-se assim entre dúvidas e conquistas, até então desprezadas pelo pai. É necessário ressignificar o filho com deficiência na família deficiente de compreensão, impactada pela dor do não conhecido, apenas daquilo que o pai já suspeitara no dia do nascimento: "há um erro primeiro em tudo, e ele não consegue localizá-lo" (TEZZA, 2008, p. 11). Espelho dele mesmo, o filho não cumpre o que o pai havia planejado: "O filho será a prova definitiva de minhas qualidades" (TEZZA, 2008, p. 14-15).

Um índice de que a eternidade do filho se instaurou no pai é nítido em: "em vez de sentir náusea da imagem - a invencível viscosidade das relações humanas -, ele sorri diante daquele pequeno joelho respirante e empacotado do outro lado do vidro: isso parece bom e bonito, o filho da primavera. Relembrou a data: madrugada do dia 3 de novembro de 1980" (TEZZA, 2008, p. 21).

Cresce nele, pai, o sentido de pertencimento que irá tomá-lo por inteiro: “O pai ainda não sabe, mas começa a ter uma ideia de filho, a desenhar-lhe uma hipótese. Como 
se, ainda muito palidamente, a sombra da paternidade começasse enfim a cair sobre ele" (p.68).

Pai e mãe lutam para alcançar a reabilitação do filho. Nessa troca, crescem os três: “ainda não é exatamente um filho. O pai não sabe disso, mas o que ele quer é que aquela criança trissômica conquiste o seu lugar na tribo". (TEZZA, 2008, p. 95); "Várias vezes por dia, em sessões de cinco minutos, a criança é colocada sobre a mesa da sala, de bruços. De um lado, ele; de outro, a mulher." (TEZZA, 2008, p. 96). A família aumenta com a chegada de uma nova criança: a filha. Ele sente um ar de normalidade aquele grupo. Mas sente também a fragilidade da relação com a mulher: "Até quando a mulher o aguentará? Até quando ele aguentará a mulher?” (TEZZA, 2008, p. 116).

A família, com o passar do tempo, vai se adequando, no entanto, ele deve se ausentar daquele núcleo em busca de condições de trabalho mais seguras. Por dois anos, só se encontram nos finais de semana. Nesse tempo, o pai, professor universitário, sente-se mais seguro. A segunda filha, sem nenhuma condição especial, agrega à família um elemento positivo. Nas brincadeiras, ela assume o papel de mãe, como costumam as meninas fazerem, conferindo ao irmão o papel de ser ele mesmo:

Tudo incompreensível. Só a irmã, parece, entende o que ele diz, cuidando das coisas dela, mas com o ouvido atento - e frequentemente promove ela mesma outro teatro, como atriz e diretora de cena, reproduzindo sem saber a vida que leva, teatro e vida são a mesma coisa, e de certo modo trazendo à realidade o irmão que, dócil, sempre aceita de bom grado os papéis que tem de assumir, eu são sempre dele mesmo, incrivelmente paciente com a impaciência eventual da irmã. "Você fique aqui! Irmão, não saia daí! Eu sou tua mãe! Isso, bem assim! Muito bem!" (TEZZA, 2008, p. 162).

A família, inicialmente, uma impossibilidade, constrói-se e segue a eternidade dos dias de uma infância preservada. A mãe, "com paciência infinita, vai construindo o cuidado e o aprendizado que serão a autonomia de filho anos depois, mas por enquanto estão só no caminho" (p. 164). Ao ser encontrado após o segundo episódio de desaparecimento, fica flagrante para os soldados o sentido de pertencimento daquela criança à mãe. Ao vê-la, o filho, efusivamente, a chama de mãezuca, todo afeto e entrega a seus abraços.

O retrato dessa família, quase em cacos, foi se tornando um mosaico amoroso e belo, uma construção em meio a dificuldades, tropeços e provas, cada um sendo testado em seus limites. Peças encaixadas, o pai e o filho, a mãe e o filho, a irmã e o irmão. Peter Pan mora com eles e faz parte do jogo de aprendizado naquele apartamento, que é seu território. 
A família, assim constituída, parece pacificada e segue o curso da vida, tal qual um jogo do qual fazem parte e ao qual também assistem. Metaforicamente, o jogo não terminou. A vida segue com seus percalços. Pai e filho juntos, frente à televisão, unem-se no gosto pelo futebol, torcem pelo mesmo time e, de certa maneira, são um o reflexo do outro: "Bandeira rubro-negra devidamente desfraldada na janela, guerreiros de brincadeira, vão enfim para a frente da televisão — o jogo começa mais uma vez. Nenhum dos dois tem a mínima ideia de como vai acabar, e isso é muito bom” (TEZZA, 2008, p. 222).

O desfecho do romance indica que o desafio a princípio rejeitado foi aceito e o temor de que "daquela coisa mal-amassada surja como que por encanto algum ser humano, só pela força do tempo (TEZZA, 2008, pp. 73-4) não se cumpriu. Venceu, nessa partida, a aceitação e o duro lapidar diário da relação amorosa. E a família, ainda que estilhaçada, sobreviveu.

\section{REFERÊNCIA}

TEZZA, Cristovão. O filho eterno. Rio de Janeiro: Record, 2008. 